\title{
Inactividad física y obesidad ¿Cuál es su repercusión en el gasto económico de diabetes mellitus 2 en Chile?
}

\section{Physical inactivity and obesity: What are the implications for diabetes expenditures in Chile?}

Dear Editor,

More than 387 million people type 2 diabetes (T2D) in the world, a figure that is expected to increase to 592 million by the year 2035. In Chile, the prevalence of diabetes increased by 3\% between 1980 and 2014 (from $7.8 \%$ to $10.8 \%$ in women and from $7.2 \%$ to $10.2 \%$ in men) $)^{1,2}$. At a global level, the economic costs associated with the care of patients with T2D was 612 billion dollars in 2014, corresponding to $11 \%$ of total health spending worldwide. In Chile, it is estimated that 21.2 billion dollars were spent on medical care in the same year, of which $10.2 \%$ (equivalent to 2.1 billion dollars) corresponded to expenses associated with T2D, that is, an average of \$1,427 per person with diabetes. The cost of this pathology is not only economic, as it is estimated that in Chile 25 people die each day from causes associated with this pathology $y^{1-3}$.

The increase in T2D observed in Chile is attributed, among other causes, to the ageing of the population, urbanization, and changes in the lifestyles of people that directly affect their development; among them, obesity, and consumption of processed foods, physical inactivity and sedentary behaviours. As a country, the biggest challenge we must face is to correctly determine the guidelines to stop the incidence of this pathology and to face, in a timely and effective way, the associated reversible risk factors. Through the National Health Survey 2009-2010 we know that $27.4 \%$ of the population is obese, $19.8 \%$ is inactive and $35.9 \%$ present sedentary risk behaviours ( $>4$ hours per day sitting $)^{4}$. The biggest problem we face is that a large part of our population has not only one, but two or more risk factors, which, when united, present a synergistic increase in the possible development of diabetes. It has been determined that people who are obese and sedentary are 3 times more likely to be diabetic; and those who are obese and inactive are 6 times more likely to develop this disease when compared with people with a normal body mass index (BMI), who are active and with low sedentary behavior $^{5,6}$.

Ding et al.7 reported that in 2013 the total cost associated with physical inactivity in Chile was 103 million dollars per year, estimating 69.2 million in directs costs and 34.1
Fanny Petermann ${ }^{1}$, Ana María Leiva², María Adela Martínez ${ }^{3}$, Carlos Salas ${ }^{4}$, Alex Garrido-Méndez ${ }^{5}$, Cristian Luarte-Rocha ${ }^{5}$, Ximena Díaz ${ }^{6}$, Cristóbal Cuadrado ${ }^{7}$, Carlos Celis-Morales ${ }^{1,8}$.

\footnotetext{
1. BHF Glasgow Cardiovascular Research Centre Institute of Cardiovascular and Medical Science, University of Glasgow, United Kingdom.

2. Instituto de Anatomía, Histología y Patología, Facultad de Medicina, Universidad Austral de Chile. Valdivia, Chile.

3. Instituto de Farmacia, Facultad de Ciencias, Universidad Austral de Chile. Valdivia, Chile. 4. Departamento de Educación Física. Facultad de Educación. Universidad de Concepción. Concepción, Chile. 5. Escuela de Educación Física, Universidad San Sebastián. Concepción, Chile.

6. Grupo de Investigación Calidad de Vida, Ciencias de la Educación, Universidad del Bío-Bío, Chillán, Chile.

7. Escuela de Salud Pública, Universidad de Chile. Santiago, Chile. 8. Centro de Investigaciones en Fisiología Integrada y Salud, Universidad Mayor. Santiago, Chile.

Dirigir correspondencia a: Carlos Celis-Morales. Glasgow Cardiovascular Research Centre, Institute of Cardiovascular and Medical Science. University of Glasgow. Glasgow. United Kingdom G12 8TA. Tel: 4401413304201. Email: carlos.celis@glasgow.ac.uk
}

Este trabajo fue recibido el 22 de agosto de 2017. Aceptado para ser publicado: 06 de septiembre de 2017.

million dollars in indirect costs; equivalent to $0.23 \%$ of the total budget associated with medical care in our country. Of the total direct cost associated with physical inactivity; 50.6 million dollars corresponded to expenses in T2D ${ }^{7}$. On the other hand, the economic cost associated with obesity in Chile corresponds to $2.2 \%$ of total health expenditures; it is estimated that this expense will increase to $4 \%$ in the 
year 2030. In turn, for direct costs associated with obesity, $9.5 \%$ are for T2D expenses, which is one of the main pathologies where resources are directed ${ }^{8}$. If we add to the costs mentioned above, the social and economic expenses and the repercussions at the individual and family level associated with diabetes, such as premature death, ocular, renal or cardiovascular complications; we must ask ourselves, what are the total costs that we are assuming for this disease? We know that the consequences of non-communicable diseases and their risk factors are distributed unequally, generating a greater impact in the most vulnerable groups of society ${ }^{9}$. This only increases the gaps in life expectancy and quality of life of the population. T2D, therefore, not only generates a great cost for society as a whole, but those costs are distributed unequally.

Healthy eating habits, physical activity and decreasing sitting time, should not be a task or a sacrifice that must be made. Adopting healthy lifestyles should be part of the daily life of everyone, like waking up, going to work or doing household chores. Thus, it is necessary to modify the environments in which people's lives take place, facilitating the adoption of healthier lifestyles.

It is clear that there are many challenges and pending tasks, but investing in prevention could have a high impact in reducing the economic cost associated with T2D and other pathologies in Chile. A recent study estimated that for every dollar invested in prevention programs, the government saves \$14 in direct and indirect costs associated with health expenditures ${ }^{10}$. Given the evidence, it is clear how essential it is to invest in promotion and prevention, since it is one of the most feasible ways to reduce the economic costs associated with chronic noncommunicable diseases such as T2D.

\section{REFERENCES}

1. da Rocha Fernandes J, Ogurtsova K, Linnenkamp U, Guariguata L, Seuring T, Zhang $P$, et al. IDF Diabetes Atlas estimates of 2014 global health expenditures on diabetes. Diabetes Res Clin Pract 2016; 117: 48-54.

2. MINSAL. Distribution of health expenditure due to illness, age and sex at the tertiary care level in Chile, 2014. Final Report. Ministerio de Salud, Gobierno de Chile. 2016.

3. MINSAL. The Diabetes Challenge in Chile. Ministerio de Salud, Gobierno de Chile. 2015.

4. MINSAL. National Health Survey 2009-2010. Chile: Ministerio de Salud; 2010.

5. Diaz X, Petermann F, Salas C, Garrido-Méndez A, et al. Effects of physical activity on the association between obesity and diabetes mellitus type 2: results of the National Health Survey 2009-2010. Rev Med Chil 2017; 145.

6. Petermann F, Garrido-Méndez A, Díaz X, Leiva A, Martínez $M$, Poblete $F$, et al. Time allocated to sitting and adiposity levels: What do they affect the development of Type 2 Diabetes Mellitus? Rev Med Chi 2017.

7. Ding $D$, Lawson $K D$, Kolbe-Alexander $T L$, Finkelstein EA, Katzmarzyk PT, van Mechelen $W$, et al. The economic burden of physical inactivity: a global analysis of major non-communicable diseases. Lancet 2016; 388(10051): 1311-1324.

8. Cuadrado C. The Health and Economic Burden of Obesity in Chile: An Epidemiological and Economic Simulation Model. Value in Health 2016; 19(7): A584.

9. Sommer I, Griebler U, Mahlknecht P, Thaler K, Bouskill K, Gartlehner G, et al. Socioeconomic inequalities in noncommunicable diseases and their risk factors: an overview of systematic reviews. BMC Public Health 2015 Sept 18;15: 914.

10. Masters R, Anwar E, Collins B, Cookson R, Capewell S. Return on investment of public health interventions: a systematic review. J Epidemiol Community Health 2017; 71(8): 827-834. 